\title{
Research on Growth Behavior of Calcium Carbonate Scale by Electrochemical Quartz Crystal Microbalance
}

\author{
Junlei Tang ${ }^{1}$, Dong Cao ${ }^{1}$, Yingying Wang ${ }^{1}$, Chamas Mohamad ${ }^{1}$, Longju Chen ${ }^{2}, H u$ Wang $^{2,}$ * \\ ${ }^{1}$ School of Chemistry and Chemical Engineering, Southwest Petroleum University, Chengdu 610500, \\ China \\ ${ }^{2}$ School of Material Science and Engineering, Southwest Petroleum University, Chengdu 610500, \\ China \\ *E-mail: senty78@126.com
}

doi: $10.20964 / 2017.12 .27$

Received: 1 August 2017 / Accepted: 13 October 2017 / Published: 12 November 2017

\begin{abstract}
An electrochemical quartz crystal microbalance (EQCM) was used to evaluate the scaling behavior of $\mathrm{CaCO}_{3}$ using an electrochemical method in which cathodic potential was applied to the working electrode. Accelerated scaling experiments were performed by varying the temperature and applied potential in a $3.5 \% \mathrm{NaCl}$ solution containing $200 \mathrm{mg} / \mathrm{L} \mathrm{Ca}^{2+}$ and $610 \mathrm{mg} / \mathrm{L} \mathrm{HCO}_{3}^{-}$. Scale inhibition efficiencies were also compared in the absence and presence of four scale inhibitors, including amino trimethylene phosphonic acid (ATMP), sodium hexametaphosphate (SHMP), 1-hydroxyethylidene-1, 1-diphosphonic acid (HEDP) and copolymer of phosphono and carboxylic acid (POCA). For further investigation of the scale inhibitors' inhibition properties, the growth kinetics of $\mathrm{CaCO}_{3}$ scale were investigated by injecting scale inhibitors during the scaling formation process. Additionally, to understand the mechanism of scaling inhibition, X-ray diffraction (XRD) and scanning electron microscopy (SEM) were undertaken to analyze and compare the morphologies, particle sizes, and crystal growth of $\mathrm{CaCO}_{3}$ scale at different conditions.
\end{abstract}

Keywords: scale inhibitor; calcium carbonate; morphology; crystal growth

\section{$\underline{\text { FULL TEXT }}$}

(C) 2017 The Authors. Published by ESG (www.electrochemsci.org). This article is an open access article distributed under the terms and conditions of the Creative Commons Attribution license (http://creativecommons.org/licenses/by/4.0/). 